\title{
Türkiye'de doğal olarak yetişen kır sümbülü (Bellevalia spp.) türlerinin yetiştiği topraklara ait özellikler
}

\section{Properties of the soils of Bellevalia (Bellevalia spp.) species naturel grown in flora of Turkey}

\author{
Erdinç UYSAL ${ }^{1}$ (D) Erdal KAYA ${ }^{2}$ (D) \\ ${ }^{1}$ Atatürk Bahçe Kültürleri Merkez Araştırma Enstitüsü, Toprak ve Su Kaynakları Bölümü, 77100, Yalova \\ ${ }^{2}$ Atatürk Bahçe Kültürleri Merkez Araştırma Enstitüsü, Geofit Araştırma Merkezi, 77100, Yalova
}

Sorumlu yazar (Corresponding author): E. Uysal, e-posta (e-mail): erdincuysal@ hotmail.com

Yazar(lar) e-posta (Authore-mail): erdal_kaya@msn.com

\section{MAKALE BİLGİSİ}

Alınış tarihi 12 Mart 2019

Düzeltilme tarihi 19 Nisan 2019

Kabul tarihi 26 Nisan 2019

\section{Anahtar Kelimeler:}

Kır sümbülü

Toprak

Verimlilik durumu

\begin{abstract}
ÖZ
Bu çalışma Türkiye florasında bulunan kır sümbülü cinsine ait farklı türlerin yetiştiği toprakların bazı özelliklerini belirlemek amacıyla yapılmıştır. Bu amaçla 2010-2014 yıllar arasında 19 ayrı ilden 41 adet toprak örneği alınarak materyal olarak kullanılmıştır. Alınan örneklerde bünye, $\mathrm{pH}$, tuzluluk, kireç, organik madde, alınabilir fosfor, değișebilir potasyum, kalsiyum ve magnezyum, alınabilir demir, mangan, çinko ve bakır analizleri yapılarak sonuçları değerlendirilmiştir. Elde edilen sonuçlara göre; toprak örneklerinin tamamı tuzsuz ya da hafif tuzlu topraklardan oluşmuştur. Bünye açısından yapılan değerlendirmede bitkilerin tın bünyeli toprakları tercih ettiği görülmüştür. İncelenen alanlarda toprakların çoğunlukla hafif alkalin karakterde oldukları saptanmıștır. Toprak örneklerinde $\mathrm{CaCO}_{3}$ miktarı genelde orta ve düşük seviyelerde bulunmasına karşın kirecin çok yüksek olduğu topraklara da rastlanmıştır. Toprak örneklerinin büyük oranda yüksek ya da çok yüksek organik madde içeriğine sahip oldukları belirlenmiştir. Toprakların alınabilir fosfor içerikleri 1-82 mg kg-1 arasında değişim göstermiştir. Değişebilir potasyum, kalsiyum ve magnezyum içerikleri ortalama olarak sirasıyla $1.00,38.65$ ve 3.80 me $100 \mathrm{~g}^{-1}$ olarak bulunmus olup tamamına yakını orta ya da yüksek düzeylerdedir. Mikro elementler açısından bakır ve manganın tüm topraklarda yeterli olduğu görülürken çinkonun $\% 39$, demirin ise $\% 22$ oranında eksikliği söz konusudur.
\end{abstract}

\section{ARTICLE INFO}

Received 12 March 2019

Received in revised form 19 April 2019

Accepted 26 April 2019

\section{Keywords:}

Bellevalia

Soil

Fertility status

\begin{abstract}
This study is conducted in order to determine some properties of the soils on which different species of Bellevalia genus that are natural grown in flora of Turkey. For this purpose 41 soil samples were taken from 19 provinces between 2010-2014. Texture, $\mathrm{pH}$, salinity, $\mathrm{CaCO}_{3}$, organic matter, available phosphorus, exchangeable potassium, calcium, magnesium and available iron, manganese, zinc, copper of soil samples were analyzed. According to the results of the study; all of the taken soil samples were considered within non saline or slightly saline soil class. In the evaluation, it was observed that the plants preferred the loamy texture soils. Mostly the soil samples within the observed area were determined to have light alkaline characteristics. Although the amount of $\mathrm{CaCO}_{3}$ was generally low and medium in soil samples, highly calcareous soils were also discovered. It has been determined that soil samples had high or very high levels organic matters substantially. The available phosphorus values of the soils were ranged between $1-82 \mathrm{mg} \mathrm{kg}^{-1}$. The exchangeable potassium, calcium and magnesium contents of soils were found on average $1.00,38.65$ and $3.80 \mathrm{me} 100 \mathrm{~g}^{-1}$ respectively, and almost all were at medium or high levels. In terms of micro-elements, copper and manganese were found to be sufficient in all soils, while zinc had a deficiency of $39 \%$ and iron $22 \%$.
\end{abstract}

\section{Giriş}

Türkiye oldukça fazla bitki tür çeşitliliğine sahip bir ülke olup bu çeşitlilikte geofitlerin önemli bir payı bulunmaktadır. Geofitler, toprak altında soğan, yumru ve rizom gibi gıda maddesi depo eden özelleşmiş toprak altı gövdeleri bulunduran bitkilere verilen genel isimdir (D.Ç.S.D. 1996). Türkiye florasında, 73 cinse bağlı 816 geofit türü doğal olarak yetişmektedir (Sargın ve ark. 2013). 
Kır sümbülü, Hyacinthaceae (Sümbülgiller) familyasından, çoğunlukla Akdeniz Bölgesinde (Fas, İran arasında) yayılış gösteren ve yaklaşık 50 tür ile temsil edilen bir cinstir. Türkiye'de 21 taksonu bulunur ve bunlardan 11'i endemiktir (Uzunhisarcıklı ve ark. 2013).

Türkiye gibi önemli biyolojik zenginliğine sahip ülkelerde, tür çeşitliliğinin korunması açısından doğadan sökümün azaltılması oldukça önemlidir. Uygun koşullar altında geofitlerin sürdürülebilir bir şekilde üretimlerinin yapılmasında herhangi bir engel bulunmamaktadır.

$\mathrm{Bu}$ çalışma ile Türkiye çapında tarama yapılarak kır sümbülüne ait farklı türlerin doğal yetişme ortamlarına gidilmiştir. Buralardan bitki kök bölgesinden toprak örnekleri alınarak bazı analizler yapılmış ve bu şekilde doğal ortamlarındaki toprak özellikleri hakkında bilgi edinilmesi amaçlanmıştır.

\section{Materyal ve Yöntem}

Çalışmanın materyali, Türkiye'de doğal olarak yetişen kır sümbülü (Bellevalia spp.) türlerine ait, 19 ayrı ilden yetiştikleri ortamlardan alınan, 41 adet toprak örneğidir. Örnekleme yapılırken ülke genelinde bitkinin yetiştiği tüm lokasyonlara ulaşılmaya çalışılmış ve ulaşılan tüm noktalardan örnek alınmıştır. Toprak örneklerinin alındığı yere ve bitkilere ait bilgiler Çizelge 1'de sunulmuştur.

Toprak örnekleri 2010-2014 yılları arasında bitki kök bölgesindeki 0-20 cm derinlikten, genel kurallara uygun olarak (Jackson 1958) paslanmaz çelik kürek ile alınmış ve polietilen torbalara konularak etiketlenmiştir. Laboratuvara getirilen toprak örnekleri, Kacar (1994)'ın bildirdiği şekilde analize hazırlanmıştır.

Alınan toprak örneklerinde bünye, Bouyoucos hidrometre yöntemiyle kum, kil ve silt oranları belirlenerek tekstür sınıfları saptanmıștır (Bouyoucos 1951). Toprak pH's1, 1:2.5 toprak-su karışımında cam elektrotlu pH metre ile (Jackson 1958), elektriksel iletkenlik aynı karışımda iletkenlik ölçer ile ölçülmüştür (Richards 1954). Kireç, Hızalan ve Ünal (1966) tarafından açıklandığ şekilde Scheibler kalsimetresiyle, organik madde; Modifiye Walkley-Black yöntemine göre yapılmıştır

Çizelge 1. Alınan toprak örneklerinin alındığı yere ve bitki türlerine ait bilgiler.

Table 1. Information about the plants and the locations from where the soil samples were taken.

\begin{tabular}{|c|c|c|c|}
\hline Numara & Alındığg y1l & Alındığı yer & Tür adı \\
\hline 1 & 2013 & Mardin & Bellevalia anatolica B.Mathew\&N.Özhatay \\
\hline 2 & 2013 & Çorum & Bellevalia clusiana Griseb. \\
\hline 3 & 2013 & Erzincan & Bellevalia crassa Wendelbo \\
\hline 4 & 2011 & Kırklareli & Bellevalia edirnensis N.Özhatay \& Mathew \\
\hline 5 & 2014 & Erzurum & Bellevalia forniculata (Fomin) Deloney \\
\hline 6 & 2014 & Ardahan & Bellevalia forniculata (Fomin) Deloney \\
\hline 7 & 2013 & Erzincan & Bellevalia gracilis Feinbrun \\
\hline 8 & 2013 & Siirt & Bellevalia gracilis Feinbrun \\
\hline 9 & 2013 & Siirt & Bellevalia gracilis Feinbrun \\
\hline 10 & 2012 & Ağrı & Bellevalia kurdistanica Feinbrun \\
\hline 11 & 2013 & Van & Bellevalia kurdistanica Feinbrun \\
\hline 12 & 2013 & Erzincan & Bellevalia longistyla (Miscz.) Grossh. \\
\hline 13 & 2011 & Karaman & Bellevalia mathewii N.Özhatay \& B.Koçak \\
\hline 14 & 2012 & Karaman & Bellevalia mathewii N.Özhatay \& B.Koçak \\
\hline 15 & 2011 & Antalya & Bellevalia mathewii N.Özhatay\&B. Koçak \\
\hline 16 & 2011 & Karaman & Bellevalia mathewii N.Özhatay\&B. Koçak \\
\hline 17 & 2012 & Karaman & Bellevalia mathewii N.Özhatay\&B. Koçak \\
\hline 18 & 2012 & Antalya & Bellevalia mathewii N.Özhatay\&B. Koçak \\
\hline 19 & 2013 & Antalya & Bellevalia mathewii N.Özhatay\&B. Koçak \\
\hline 20 & 2011 & İçel & Bellevalia modesta Wendelbo \\
\hline 21 & 2011 & İçel & Bellevalia modesta Wendelbo \\
\hline 22 & 2011 & İçel & Bellevalia modesta Wendelbo \\
\hline 23 & 2013 & Kars & Bellevalia paradoxa \\
\hline 24 & 2013 & Artvin & Bellevalia paradoxa (Fisch. \& Mey.) Boiss. \\
\hline 25 & 2011 & Ardahan & Bellevalia paradoxa (Fisch.\&Mey) Boiss. \\
\hline 26 & 2013 & Van & Bellevalia paradoxa (Fisch.\&Mey) Boiss. \\
\hline 27 & 2013 & Van & Bellevalia paradoxa (Fisch.\&Mey) Boiss. \\
\hline 28 & 2011 & Erzurum & Bellevalia pycnantha (C. Koch) A. Los \\
\hline 29 & 2012 & Erzurum & Bellevalia pycnantha (C. Koch) A. Los. \\
\hline 30 & 2013 & Erzurum & Bellevalia sarmatica (Palas ex Georgi) Woronow \\
\hline 31 & 2011 & Erzurum & Bellevalia sarmatica (Palas ex Georgi) Woronow \\
\hline 32 & 2012 & Erzurum & Bellevalia sarmatica (Palas ex Georgi) Woronow \\
\hline 33 & 2012 & Erzurum & Bellevalia sarmatica (Palas ex Georgi) Woronow \\
\hline 34 & 2013 & Kars & Bellevalia sarmatica (Palas ex Georgi) Woronow \\
\hline 35 & 2014 & İzmir & Bellevalia sp. \\
\hline 36 & 2014 & Kahramanmaraş & Bellevalia sp. \\
\hline 37 & 2010 & Van & Bellevalia sp. \\
\hline 38 & 2013 & Kayseri & Bellevalia sp. (nova) \\
\hline 39 & 2012 & Antalya & Bellevalia tauri Feinbrun \\
\hline 40 & 2012 & Muğla & Bellevalia trifoliata (Ten.) Kunth \\
\hline 41 & 2012 & Hatay & Bellevalia trifoliata (Ten.) Kunth \\
\hline
\end{tabular}


(Jackson 1962). Alınabilir fosfor, 0.5 M sodyum bikarbonat (pH: 8.5) ile ekstraksiyon yöntemiyle (Olsen ve ark. 1954), değişebilir potasyum, kalsiyum, magnezyum; $1 \mathrm{~N}$ Amonyum Asetat (pH: 7.0) ekstraksiyonu ile (FAO 1980), alınabilir demir, bakır, çinko ve mangan; DTPA (pH: 7.3) ekstraksiyonu ile (Lindsay ve Norwell 1978) elde edilen ekstraktların ICP-OES cihazında okunması ile saptanmıştır.

\section{Bulgular ve Tartışma}

Çalışma süresince alınan toprakların bazı fiziksel ve kimyasal özelliklerine ait analiz sonuçları Çizelge 2'de, bu sonuçlara ait en küçük, en büyük ve ortalama değerler Çizelge 3'de gösterilmiştir. Toprak örneklerinin sinıflandırılmasında kullanılan sınır değerler ve bu değerlere göre yapılan değerlendirmeler ise Çizelge 4'te verilmiştir.

Yapılan bünye analizi sonuçlarına göre örneklerin genel olarak tın bünyeye sahip topraklardan oluştuğu görülmektedir. \%2.4'ü kil bünyeye sahip olan toprakların kalan kısmı şu şekilde sıralanmıştır; \%34.15 kumlu killi tın, \%21.95 kumlu tın, $\% 21.95$ tın ve \% 19.51 killi tın'dır. Toprakların kil oranları $\% 13.63-40.92$, silt oranlar1 \%8.33-42.42 ve kum oranları \%35.79-74.04 değerleri arasında değişmiștir. Ortalama olarak ise kil, silt ve kum oranları sirasiyla, \%23.50, \%24.40 ve \%52.10 olarak belirlenmiştir. Elde edilen değerlere göre kır sümbülü bitkisinin kum oranı görece yüksek tın bünyeli toprakları tercih ettiğini söyleyebiliriz. Kahramanmaraş doğal florasında yetişen salep orkide bitkisinin doğal toprak özelliklerinin incelendiği bir çalışmada toprak bünyesi oranları $\% 51.47$ kum, \%29.16 silt ve \%19.37 kil olarak bulunurken araştırıcılar belirledikleri bünye sınıfını tın olarak bildirmişlerdir (Palaz ve ark. 2018). Van yöresinde farklı orkide türleri ile yapılan benzer bir çalışmada topraklarda kum oranlarının \%15.2-58.0 arasında, silt oranlarının \%18-66 arasında ve kil oranlarının \%8.4-24.8 arasında değiştiği bildirilmiştir (Çı̆̆ ve Yılmaz 2015). Diğer çalışma sonuçlarının da gösterdiği gibi kum oranlarının silt ve kil'e oranla topraklarda daha fazla bulunduğu ortaya çıkmaktadır.

Çizelge 2. Alınan toprak örneklerinin bazı fiziksel ve kimyasal özellikleri.

Table 2. Some physical and chemical properties of soil samples were taken.

\begin{tabular}{|c|c|c|c|c|c|c|c|c|c|c|c|c|c|}
\hline : & 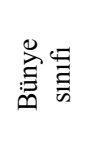 & $\frac{T}{2}$ & 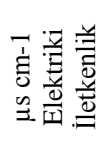 & ஓ ల্ত & 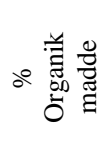 & 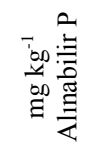 & 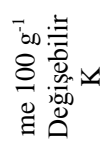 & 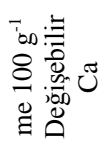 & 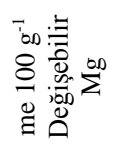 & 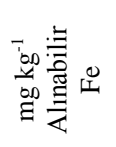 & 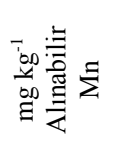 & 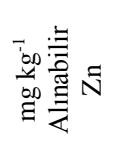 & 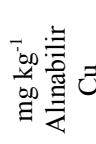 \\
\hline 1 & CL & 8.15 & 195 & 5.23 & 5.80 & 4.38 & 0.41 & 49.34 & 6.68 & 5.58 & 4.83 & 0.62 & 1.05 \\
\hline 2 & $\mathrm{~L}$ & 8.30 & 491 & 16.71 & 2.14 & 1.72 & 0.32 & 47.66 & 8.66 & 4.29 & 7.56 & 0.20 & 2.55 \\
\hline 3 & SCL & 7.78 & 155 & 0.39 & 3.60 & 1.37 & 0.37 & 9.66 & 7.90 & 13.45 & 28.51 & 0.59 & 1.17 \\
\hline 4 & SL & 7.26 & 263 & 7.93 & 5.66 & 43.38 & 0.98 & 28.54 & 3.65 & 23.54 & 47.98 & 2.35 & 1.88 \\
\hline 5 & SCL & 7.60 & 228 & 1.01 & 7.30 & 9.00 & 2.16 & 42.89 & 9.76 & 12.17 & 20.32 & 0.55 & 1.67 \\
\hline 6 & SCL & 7.22 & 165 & 0.00 & 16.96 & 7.09 & 0.60 & 32.09 & 8.30 & 48.90 & 44.66 & 3.16 & 3.64 \\
\hline 7 & $\mathrm{CL}$ & 8.08 & 163 & 52.14 & 4.30 & 5.36 & 0.46 & 43.64 & 1.17 & 6.92 & 6.96 & 0.77 & 1.17 \\
\hline 8 & $\mathrm{CL}$ & 8.30 & 131 & 4.22 & 3.14 & 0.73 & 1.25 & 57.18 & 3.85 & 4.29 & 3.73 & 0.23 & 1.40 \\
\hline 9 & $\mathrm{~L}$ & 8.38 & 204 & 19.31 & 2.32 & 0.55 & 0.58 & 47.04 & 1.38 & 3.47 & 3.63 & 0.19 & 2.20 \\
\hline 10 & SCL & 6.86 & 343 & 0.00 & 3.26 & 15.71 & 0.90 & 10.76 & 2.10 & 15.30 & 26.92 & 1.01 & 0.84 \\
\hline 11 & SL & 8.38 & 182 & 5.63 & 3.81 & 2.19 & 1.27 & 42.83 & 3.49 & 3.62 & 5.31 & 0.33 & 1.35 \\
\hline 12 & SL & 7.50 & 242 & 0.82 & 8.70 & 10.22 & 0.60 & 17.04 & 1.72 & 17.79 & 23.17 & 1.70 & 2.35 \\
\hline 13 & SL & 7.81 & 322 & 0.39 & 2.24 & 2.33 & 0.34 & 31.71 & 3.47 & 8.98 & 17.97 & 0.42 & 1.43 \\
\hline 14 & $\mathrm{CL}$ & 7.96 & 298 & 5.10 & 3.92 & 4.52 & 0.39 & 46.40 & 1.32 & 12.00 & 20.30 & 0.58 & 1.11 \\
\hline 15 & $\mathrm{~L}$ & 7.44 & 410 & 10.31 & 11.28 & 10.53 & 1.31 & 57.24 & 3.47 & 24.39 & 38.04 & 2.00 & 1.84 \\
\hline 16 & $\mathrm{C}$ & 7.82 & 312 & 1.95 & 3.60 & 2.67 & 0.67 & 39.91 & 1.01 & 34.49 & 88.95 & 0.99 & 0.88 \\
\hline 17 & SCL & 7.33 & 318 & 0.59 & 4.18 & 4.34 & 0.60 & 17.66 & 1.00 & 11.75 & 20.15 & 0.53 & 0.74 \\
\hline 18 & $\mathrm{CL}$ & 7.40 & 319 & 3.81 & 11.28 & 21.43 & 1.82 & 36.45 & 1.91 & 23.81 & 45.55 & 3.15 & 1.28 \\
\hline 19 & SCL & 8.09 & 147 & 4.78 & 5.66 & 4.60 & 0.56 & 50.59 & 2.95 & 11.66 & 17.04 & 1.10 & 1.90 \\
\hline 20 & SCL & 8.05 & 168 & 27.63 & 4.84 & 7.30 & 0.47 & 53.14 & 1.59 & 5.62 & 11.30 & 0.97 & 1.11 \\
\hline 21 & SL & 8.01 & 169 & 9.24 & 20.44 & 60.54 & 1.59 & 65.92 & 3.18 & 34.35 & 36.55 & 5.12 & 1.54 \\
\hline 22 & SCL & 8.25 & 106 & 1.40 & 8.26 & 15.49 & 0.73 & 49.12 & 2.12 & 15.26 & 42.08 & 1.77 & 1.91 \\
\hline 23 & SCL & 6.13 & 242 & 0.55 & 14.36 & 8.54 & 0.92 & 24.69 & 3.56 & 54.46 & 58.63 & 3.19 & 1.87 \\
\hline 24 & SL & 5.70 & 148 & 0.00 & 24.00 & 9.72 & 0.83 & 18.84 & 2.85 & 120.89 & 48.24 & 3.96 & 1.23 \\
\hline 25 & SL & 5.70 & 140 & 0.00 & 24.00 & 8.92 & 1.02 & 17.37 & 2.01 & 83.25 & 52.85 & 1.89 & 0.78 \\
\hline 26 & SL & 7.74 & 277 & 0.60 & 8.48 & 61.18 & 2.05 & 32.75 & 2.37 & 17.97 & 16.15 & 1.43 & 1.09 \\
\hline 27 & $\mathrm{~L}$ & 8.29 & 316 & 24.54 & 11.64 & 16.25 & 2.29 & 46.15 & 7.77 & 7.32 & 27.33 & 2.46 & 2.15 \\
\hline 28 & $\mathrm{CL}$ & 7.91 & 320 & 2.75 & 9.40 & 24.61 & 2.94 & 24.28 & 1.79 & 18.45 & 13.33 & 1.02 & 0.82 \\
\hline 29 & SCL & 7.02 & 334 & 0.39 & 3.46 & 9.99 & 0.46 & 16.88 & 3.93 & 15.32 & 22.00 & 0.56 & 1.31 \\
\hline 30 & SCL & 8.41 & 465 & 3.55 & 1.02 & 2.18 & 0.80 & 33.49 & 5.70 & 3.98 & 5.81 & 0.22 & 1.43 \\
\hline 31 & SCL & 7.53 & 216 & 0.39 & 6.94 & 10.72 & 1.24 & 31.16 & 5.68 & 15.31 & 37.45 & 0.96 & 2.13 \\
\hline 32 & $\mathrm{~L}$ & 8.27 & 197 & 13.94 & 2.72 & 3.21 & 0.74 & 47.38 & 5.34 & 3.74 & 8.03 & 0.16 & 2.52 \\
\hline 33 & $\mathrm{~L}$ & 8.59 & 220 & 15.48 & 2.62 & 2.50 & 0.48 & 44.45 & 8.11 & 1.91 & 4.13 & 0.10 & 1.50 \\
\hline 34 & SCL & 7.69 & 145 & 0.00 & 4.94 & 3.10 & 1.27 & 21.84 & 3.08 & 5.82 & 14.28 & 0.53 & 1.06 \\
\hline 35 & $\mathrm{CL}$ & 7.38 & 195 & 36.37 & 5.96 & 7.18 & 0.84 & 47.27 & 3.99 & 3.70 & 4.69 & 1.56 & 1.44 \\
\hline 36 & $\mathrm{~L}$ & 8.16 & 139 & 5.53 & 6.26 & 25.06 & 0.66 & 41.54 & 0.96 & 10.47 & 8.08 & 0.91 & 1.83 \\
\hline 37 & SL & 7.80 & 203 & 6.45 & 13.42 & 81.95 & 1.30 & 43.10 & 2.61 & 17.71 & 68.28 & 2.58 & 1.63 \\
\hline 38 & $\mathrm{~L}$ & 8.26 & 163 & 22.73 & 3.70 & 2.56 & 1.92 & 59.44 & 2.90 & 3.22 & 4.77 & 0.45 & 0.93 \\
\hline 39 & $\mathrm{CL}$ & 8.09 & 190 & 39.56 & 5.80 & 5.91 & 0.43 & 53.17 & 1.69 & 14.45 & 11.36 & 0.75 & 2.19 \\
\hline 40 & SCL & 7.85 & 271 & 6.85 & 14.22 & 6.66 & 1.19 & 47.34 & 5.55 & 14.13 & 69.08 & 3.28 & 1.76 \\
\hline 41 & $\mathrm{~L}$ & 7.87 & 308 & 13.99 & 9.14 & 21.06 & 1.15 & 56.85 & 5.13 & 27.86 & 62.92 & 1.06 & 2.04 \\
\hline
\end{tabular}


Toprak reaksiyonu açısından ortalama 7.72 olarak saptanan pH değeri tüm topraklar arasında 5.70-8.59 değerleri arasında değişmiştir. Eyüpoğlu (1999)'a göre yapılan sınıflandırmada toprakların \%7.3'ü hafif asit, \%90.2'si hafif alkalin, \%2.4'ü ise kuvvetli alkalin reaksiyona sahip bulunmuştur. Türkiye'de geniş bir yayılış alanı gösteren önemli geofit cinslerinden birisi olan Asphodeline (çiriş otu) ile yapılan bir çalışmada ülke genelinde 25 ayrı ilden toplamda 70 adet toprak örneği alınarak incelenmiştir (Uysal ve Kaya 2018). Çalışma sonucunda pH değeri ortalama olarak 7.89 olarak bulunmuş olup, örneklerin \%82.9 gibi büyük bir oran1 hafif alkalin topraklardan oluşmuştur. Kalan örnekler \%14.3 oranında nötr, \%2.9 oranında kuvvetli alkalin karakterde bulunmuştur. Kandemir (1997), Türkiye'de bulunan bazı endemik iris türleri üzerinde yaptığ çalışmada farklı lokasyonlardan aldığı toprak örneklerinde $\mathrm{pH}$ analizleri yapmış ve türlere göre 5.85-7.60 değerleri arasında değişen sonuçlar bulmakla birlikte, çoğunlukla alınan toprakların nötr ve hafif alkalin karakterli topraklar olduğunu bildirmiştir. Çalışmamızda elde edilen sonuçlara göre diğer bazı geofit türlerinde olduğu gibi incelenen toprakların çoğunlukla hafif alkalin karakterli olduğu görülmektedir.

Topraklar tuzluluk değerleri yönünden incelendiğinde (Dellavalle 1992) alınan örneklerin \%92.7'inin tuzsuz topraklar sınıfına girdiği bunun yanında kalan \%7.3'ünün ise hafif tuzlu topraklardan oluştuğu saptanmıştır. Farklı geofit cinslerinde yapılan benzer çalışmalarda incelenen toprak örneklerinin çok büyük oranda tuzsuz topraklardan oluştuğu kaydedilmiştir. Farklı dağ lalesi türlerinde yapılan çalışmanın sonuçlarına göre tuzsuz toprakların oran1 \%95.8 olarak belirlenirken (Uysal ve Kaya 2017), acı çiğdem türleri ile yapılan ve 109 toprağın incelendiği bir diğer çalışmada bu oran \%99.1 olarak belirlenmiştir (Uysal ve Kaya 2019).

İncelenen toprakların kireç içerikleri ortalama \%9.08 olarak bulunmuştur. Yapılan genel değerlendirmede (Hızalan ve Ünal 1966) tüm toprak örneklerinin $\% 51.22$ oranında düşük ya da çok düşük kireç içerdiği görülmektedir. Bunun yanında \%26.83 oranla kireci orta seviyede içeren toprakların varlı̆̆ söz konusudur. Toprakların \%12.20'sinde kireç yüksek ve \%9.76'sında ise çok yüksek olarak bulunmuştur. Genel olarak kireç içerikleri düşük düzeylerde bulunsa da, kirecin oldukça yüksek olduğu topraklarda da bitkilerin gelişmelerini sürdürdükleri görülmüştür. Farklı geofit türleri ile yapılan çalışmalarda benzer sonuçları görmek mümkündür. Uysal ve Kaya (2019) ilkbaharda çiçeklenen farklı acı çiğdem türlerine ait doğal yetişme ortamlarından aldıkları toprakları inceledikleri çalışmada toprakların kireç içeriklerini ortalama \%11.49 olarak bulduklarını fakat bunun yanında \%57.86'ya kadar kireç içeren toprak örneklerine de rastladıklarını bildirmiş̧lerdir. Dağ lalesi için yapılan bir diğer çalışmada incelenen toprakların kireç içeriklerinin \%71.9 oranında düşük ya da çok düşük olmasına karşın \%7'sinin ise yüksek ve çok yüksek kireç içeriğine sahip olduğu belirlenmiştir (Uysal ve Kaya 2017). Araştırıcılar buldukları en yüksek kireç içeriğini \%56.60 olarak bildirmiştir.

Toprak organik maddeleri açısından yapılan sınıflandırmada (Güçdemir 2006) organik maddeyi yüksek ve çok yüksek düzeyde içeren toprakların oranı $\% 85.4$ olarak belirlenirken, $\% 12.2^{\prime}$ lik kısım orta, kalan \%2.4'lük kısım ise az miktarda organik madde içermektedir. Sonuçlardan kır sümbülü türlerinin organik madde içeriği yüksek olan alanları tercih ettiği görülmektedir. Dağ lalesi için yapılan benzer çalışmada, araştırıcılar inceledikleri 71 adet toprak örneğinin tamamının yüksek ya da çok yüksek düzeyde organik madde içerdiğini not etmişlerdir (Uysal ve Kaya 2017). Asphodeline için yapılmış çalışma sonuçlarında organik madde içeriklerinin yüksek bulunduğu toprakların oranı $\% 84.3$ olurken orta düzeyde organik madde içeren örneklerin oran $\% 10$ olarak verilmiştir (Uysal ve Kaya 2018). Araştırıcılar \%5.7'lik kısımda düşük organik madde bulduklarını kaydetmiştir.

Toprakların alınabilir fosfor içeriği bakımından yapılan sinıflandırmaya (Olsen ve ark. 1954) göre, topraklarda \%46.4 düşük veya çok düşük, \%34.1 orta, \%19.5 oranında yüksek fosfor bulunduğu belirlenmiştir. Değişebilir K bakımından incelenen topraklar Pizer (1967)'e göre sınıflandırılmıştır. Buna göre toprakların \%7.3'ü düşük, \%29.3'ü orta ve iyi, \%63.4'ünün ise yüksek ve çok yüksek düzeyde potasyum içeriğine sahip olduğu belirlenmiştir. Değişebilir $\mathrm{Ca}$ ve $\mathrm{Mg}$ içerikleri açısından toprak örnekleri FAO 1990'a göre sınıflandırılmış olup kalsiyum açısından eksiklik olmadığ belirlenirken, \%12.2 oranında magnezyum eksikliği tespit edilmiştir. Topraklardaki yeterlilik oranı kalsiyum açısından $\% 12.2$ olurken magnezyumda bu oran $\% 58.5$ olmuştur. Örneklerin \%87.8'inde kalsiyum fazla yada çok fazla bulunurken, \%29.3'ünde magnezyumun fazla bulunduğu belirlenmiştir. Makro elementler açısından yapılan benzer çalışmalarda birbirinden farklı sonuçlar bulunduğu görülmektedir. Farklı orkide türleri için Van yöresinde yapılan çalışma sonuçlarına göre toprakların fosfor içeriklerinin $6.65-18.02 \mathrm{mg} \mathrm{kg}^{-1}$ arasında değişim gösterdiği ve genel olarak düşük ve orta seviyelerde bulunduğu bildirilmiştir (Çığ ve

Çizelge 3. Analiz sonuçlarına ait en küçük, en büyük ve ortalama değerler.

Table 3. The highest, lowest and average values concerning the results of analysis.

\begin{tabular}{|c|c|c|c|}
\hline Toprak Özellikleri & En küçük & En yüksek & Ortalama \\
\hline$\%$ Kil & 13.63 & 40.92 & 23.50 \\
\hline$\%$ Silt & 8.33 & 42.42 & 24.40 \\
\hline$\%$ Kum & 35.79 & 74.04 & 52.10 \\
\hline $\mathrm{pH}$ & 5.7 & 8.59 & 7.72 \\
\hline $\mathrm{EC}_{25}\left(\mu \mathrm{mhos} \mathrm{cm}^{-1}\right)$ & 106 & 491 & 240 \\
\hline $\mathrm{CaCO}_{3}(\%)$ & 0.00 & 52.14 & 9.08 \\
\hline Organik madde, $(\%)$ & 1.02 & 24.00 & 7.68 \\
\hline Alınabilir $\mathrm{P}\left(\mathrm{mg} \mathrm{kg}^{-1}\right)$ & 0.55 & 81.95 & 13.34 \\
\hline Değişsebilir K (me $100 \mathrm{~g}^{-1}$ ) & 0.32 & 2.94 & 1.00 \\
\hline Değişebilir Ca (me $\left.100 \mathrm{~g}^{-1}\right)$ & 9.66 & 65.92 & 38.65 \\
\hline Değişebilir $\mathrm{Mg}\left(\mathrm{me} 100 \mathrm{~g}^{-1}\right)$ & 0.96 & 9.76 & 3.80 \\
\hline Alınabilir $\mathrm{Fe}\left(\mathrm{mg} \mathrm{kg}^{-1}\right)$ & 1.91 & 120.89 & 19.06 \\
\hline Alınabilir Mn (mg kg $\left.{ }^{-1}\right)$ & 3.63 & 88.95 & 26.80 \\
\hline Alınabilir $\mathrm{Zn}\left(\mathrm{mg} \mathrm{kg}^{-1}\right)$ & 0.10 & 5.12 & 1.35 \\
\hline Alınabilir $\mathrm{Cu}\left(\mathrm{mg} \mathrm{kg}^{-1}\right)$ & 0.74 & 3.64 & 1.58 \\
\hline
\end{tabular}


Çizelge 4. Toprak örneklerinin bazı fiziksel ve kimyasal özelliklerine göre sınıflandırılması.

Table 4. Classifications about physical and chemical characteristics of the soil samples.

\begin{tabular}{|c|c|c|c|}
\hline Toprak Özelliği & Sınır Değeri & Değerlendirme & $\%$ \\
\hline \multirow{11}{*}{ Bünye sınıfları, (Bouyoucos 1951) } & & Kum (S) & 0 \\
\hline & & Tınlı kum (LS) & 0 \\
\hline & & Kumlu tın (SL) & 21.95 \\
\hline & & $\operatorname{Tin}(\mathrm{L})$ & 21.95 \\
\hline & & Siltli tın (SiL) & 0 \\
\hline & & Silt (Si) & 0 \\
\hline & & Kumlu killi tın (SCL) & 34.15 \\
\hline & & Killi tın (CL) & 19.51 \\
\hline & & Siltli killi tın (SiCL) & 0 \\
\hline & & $\begin{array}{l}\text { Kumlu kil (SC) } \\
\text { Siltli kil (SiC) }\end{array}$ & $\begin{array}{l}0 \\
0\end{array}$ \\
\hline & & $\operatorname{Kil}(\mathrm{C})$ & 2.44 \\
\hline \multirow{6}{*}{ pH (Eyüboğlu 1999) } & $<4.5$ & Kuvvetli asit (strongly acid) & 0.0 \\
\hline & $4.5-5.5$ & Orta Asit (moderately acid) & 0.0 \\
\hline & $5.6-6.5$ & Hafif Asit (slightly acid) & 7.3 \\
\hline & $6.6-7.5$ & Nötr (neutral) & 0.0 \\
\hline & 7.6-8.5 & Hafif Alkalin (slightly alkaline) & 90.2 \\
\hline & $>8.5$ & Kuvvetli alkalin (strongly alkaline) & 2.4 \\
\hline \multirow{5}{*}{$\mathrm{EC}_{25}, \mathrm{ds} \mathrm{m}^{-1}$ (Dellavalle 1992) } & $<400$ & Tuzsuz (non saline) & 92.7 \\
\hline & $400-800$ & Hafif Tuzlu (slightly saline) & 7.3 \\
\hline & $801-1200$ & Orta Tuzlu (moderately saline) & 0.0 \\
\hline & $1201-1600$ & Tuzlu (saline) & 0.0 \\
\hline & $1601-3200$ & Yüksek Tuzlu (strongly saline) & 0.0 \\
\hline \multirow{5}{*}{$\mathrm{CaCO}_{3}, \%$ (Hızalan ve Ünal 1966) } & $<1.0$ & Çok Düşük (very low) & 31.71 \\
\hline & $1.0-5.0$ & Düşük (low) & 19.51 \\
\hline & $5.1-15.0$ & Orta (medium) & 26.83 \\
\hline & $15.1-25.0$ & Yüksek (high) & 12.20 \\
\hline & $>25.0$ & Çok Yüksek (very high) & 9.76 \\
\hline \multirow{5}{*}{ Organik Madde, (\%, Güçdemir 2006) } & $<1.0$ & Çok Düşük (very low) & 0.0 \\
\hline & $1.0-2.0$ & Düşük (low) & 2.4 \\
\hline & $2.1-3.0$ & Orta (medium) & 12.2 \\
\hline & $3.1-4.0$ & Yüksek (high) & 19.5 \\
\hline & $>4.0$ & Çok Yüksek (very high) & 65.9 \\
\hline \multirow{4}{*}{ Alınabilir P, $\mathrm{mg} \mathrm{kg}^{-1}$ (Olsen ve ark. 1954) } & $<3.0$ & Çok Düşük (very low) & 24.4 \\
\hline & $3.0-7.0$ & Düşük (low) & 22.0 \\
\hline & $7.1-20.0$ & Orta (medium) & 34.1 \\
\hline & $>20.0$ & Yüksek (high) & 19.5 \\
\hline \multirow{6}{*}{ Değişebilir K, me $100 \mathrm{~g}^{-1}$ (Pizer 1967) } & $<0.255$ & Çok Düşük (very low) & 0.0 \\
\hline & $0.256-0.385$ & Düşük (low) & 7.3 \\
\hline & $0.386-0.510$ & Orta (medium) & 17.1 \\
\hline & $0.511-0.640$ & İyi (good) & 12.2 \\
\hline & $0.641-0.820$ & Yüksek (high) & 12.2 \\
\hline & $>0.820$ & Çok Yüksek (very high) & 51.2 \\
\hline \multirow{5}{*}{ Değişebilir Ca, me $100 \mathrm{~g}^{-1}$ (FAO 1990) } & $<1.19$ & Çok az (very low) & 0.0 \\
\hline & $1.19-5.75$ & $\mathrm{Az}$ (low) & 0.0 \\
\hline & $5.756-17.5$ & Yeter (sufficient) & 12.2 \\
\hline & $17.6-50$ & Fazla (high) & 68.3 \\
\hline & $>50$ & Çok fazla (very high) & 19.5 \\
\hline \multirow{5}{*}{ Değişebilir Mg, me $100 \mathrm{~g}^{-1}$ (FAO 1990) } & $<0.42$ & Çok az (very low) & 0.0 \\
\hline & $0.42-1.33$ & $\mathrm{Az}$ (low) & 12.2 \\
\hline & $1.34-4.00$ & Yeter (sufficient) & 58.5 \\
\hline & $4.1-12.5$ & Fazla (high) & 29.3 \\
\hline & $>12.5$ & Çok fazla (very high) & 0.0 \\
\hline \multirow{3}{*}{ Alınabilir Fe, mg kg ${ }^{-1}$ (Lindsay ve Norvell 1978) } & $<2.5$ & Noksan (low) & 2.40 \\
\hline & $2.5-4.5$ & Noksanlık görülebilir (critical) & 19.60 \\
\hline & $>4.5$ & İyi (good) & 78.00 \\
\hline \multirow[t]{2}{*}{ Alınabilir Cu, $\mathrm{mg} \mathrm{kg}^{-1}$ (Lindsay ve Norvell 1978) } & $<0.2$ & Yetersiz (insufficient) & 0 \\
\hline & $>0.2$ & Yeterli (sufficient) & 100.0 \\
\hline \multirow{4}{*}{ Alınabilir Mn, $\mathrm{mg} \mathrm{kg}^{-1}$ (FAO 1990) } & $<0.2$ & Çok az (very low) & 0 \\
\hline & $0.2-0.7$ & $\mathrm{Az}$ (low) & 0 \\
\hline & $0.7-5.0$ & Yeterli (sufficient) & 14.60 \\
\hline & $>5$ & Fazla (high) & 85.40 \\
\hline \multirow{5}{*}{ Alınabilir Zn, mg kg-1 (FAO 1990) } & $>0.2$ & Çok az (very low) & 0.0 \\
\hline & $0.2-0.7$ & $\mathrm{Az}$ (low) & 39.0 \\
\hline & $0.7-2.4$ & Yeterli (sufficient) & 41.5 \\
\hline & $2.4-8.0$ & Fazla (high) & 19.5 \\
\hline & $>8.0$ & Çok fazla (very high) & 0.0 \\
\hline
\end{tabular}


Yılmaz 2015). Araştırıcılar potasyum içeriklerini 360-955 $\mathrm{mg} \mathrm{kg}^{-1}$ arasında bildirmiş olup tüm örneklerin yüksek potasyum içerdiğini ifade etmişlerdir. Aynı çalışmanın magnezyum sonuçlarında, değerlerin $257-2462 \mathrm{mg} \mathrm{kg}^{-1}$ arasında değiştiği ve yeterli ya da yüksek düzeyde bulunduğu bildirilmiştir. Salep orkide bitkisinin Kahramanmaraş doğal florasında toprak özelliklerinin incelendiği çalışmada ortalama olarak fosfor içeriği $4.26 \mathrm{~kg} \mathrm{da}^{-1}$, potasyum içeriği $59.09 \mathrm{~kg} \mathrm{da}$ 1, kalsiyum içeriği $846 \mathrm{mg} \mathrm{kg}^{-1}$ ve magnezyum içeriği $197 \mathrm{mg}$ $\mathrm{kg}^{-1}$ olarak belirlenmiştir (Palaz ve ark. 2018). Araştırıcılar çalışmada elde ettikleri sonuçlara göre fosfor ve kalsiyum içeriklerinin düşük, magnezyumun yeterli, potasyumun ise yüksek değerlerde bulunduğunu ifade etmişlerdir.

Toprakların mikro element içerikleri de belirlenmiş olup demir ve bakır içerikleri Lindsay ve Norvell (1978), çinko ve mangan içerikleri FAO (1990)'a göre değerlendirilmiştir. Yapılan analizler sonucunda ortalama olarak demir içerikleri 19.06, mangan 26.80, çinko 1.35 ve bakır 1.58 olarak bulunmuştur. Sonuçlara göre örneklerin tamamında bakır yeterli düzeyde bulunurken mangan için bu oran \%14.60 olmuş, kalan \%85.40'lık kısım manganı fazla içermiştir. Demir sonuçlarına göre $\% 78$ oranında iyi düzeyde demir bulunurken kritik seviyede demir içeren örneklerin oranı \%19.60 ve eksiklik bulunanlar ise \%2.40 olarak saptanmıştır. Çinko da eksikliğin daha yüksek olduğu görülmektedir. Örneklerin \%39'unda çinko eksik bulunurken, \%19.5'inde yüksek çıkmıştır. Kalan \%41.5'lik kısımda yeterli düzeyde çinko bulunmuştur. Salep orkidesi için yapılmış çalışmada farklı topraklarda elde edilen ortalama demir miktarının $9.13 \mathrm{mg} \mathrm{kg}^{-1}$, manganın 9.98 $\mathrm{mg} \mathrm{kg}^{-1}$, çinkonun $1.49 \mathrm{mg} \mathrm{kg}^{-1}$ ve bakırın $0.27 \mathrm{mg} \mathrm{kg} \mathrm{kg}^{-1}$ bulunduğu bildirilmiştir (Palaz ve ark. 2018). Farklı orkide türleri için yapılmış başka bir çalışmada toprakların demir içerikleri 24.83-420.96 mg kg-1, mangan içerikleri 91.14$373.50 \mathrm{mg} \mathrm{kg}^{-1}$, bakır içerikleri $1.58-5.50 \mathrm{mg} \mathrm{kg}^{-1}$ ve çinko içerikleri 0.46-3.37 $\mathrm{mg} \mathrm{kg}^{-1}$ arasında değişim göstermiş̧tir (Çı̆ ve Yilmaz 2015).

\section{Sonuç}

Sonuç olarak, bu çalışma ile Türkiye'de doğal olarak yetişen farklı kır sümbülü türlerinin doğal yetişme ortamlarından alınan toprak örneklerinin incelenmesi ile bitkinin toprak istekleri hakkında bilgi edinilmesi amaçlanmıştır.

Yapılan çalışma sonucunda; alınan toprak örneklerinin tamamının tuzsuz topraklardan oluştuğu görülmüştür. Bünye açısından alınan örneklerin kum içeriklerinin daha yüksek olduğu ve genelde tın bünyeli topraklardan oluştuğu saptanmıştır. Çok büyük oranda yüksek organik madde ve düşük ya da orta düzeyde kireç içeriğine sahip olan toprakların bir kısmı ise kireci yüksek seviyelerde içermiştir. Bu yüksek seviyelerde kireç içeren topraklarda bitkilerin yetişebilmesi kirece dayanımının yüksek olduğunu düşündürmektedir. Toprak reaksiyonu açısından çok büyük oranda toprakların hafif alkalin karakter gösterdikleri saptanmıştır.

Toprakların alınabilir fosfor içerikleri $0.55-81.95 \mathrm{mg} \mathrm{kg}^{-1}$, değişebilir potasyum içerikleri $0.32-2.94 \mathrm{me} 100 \mathrm{~g}^{-1}$, değişebilir kalsiyum içerikleri $9.66-65.92$ me $100 \mathrm{~g} \mathrm{~g}^{-1}$, değişebilir magnezyum içerikleri $0.96-9.76$ me $100 \mathrm{~g}^{-1}$, alınabilir demir içerikleri 1.9-20.89 $\mathrm{mg} \mathrm{kg}^{-1}$, alınabilir mangan içerikleri 3.63-88.95 $\mathrm{mg} \mathrm{kg}^{-1}$, alınabilir çinko içerikleri $0.10-5.12$ $\mathrm{mg} \mathrm{kg}^{-1}$ ve alınabilir bakır içerikleri $0.74-3.64 \mathrm{mg} \mathrm{kg}^{-1}$, değerleri arasında değişiklik göstermiştir.

\section{Teşekkür}

Bu çalışmayı 110G007 No'lu proje kapsamında destekleyen TÜBİTAK'a teşekkür ederiz.

\section{Kaynaklar}

Bouyoucos GJ (1951) A recalibration of hydrometer method for making mechanical analysis of soils. Agronomy J. 43: 434-438.

Çı̆̆ A, Yılmaz H (2015) Van yöresinde doğal olarak yetișen farklı orkide türlerine ait toprakların bazı fiziksel ve kimyasal özellikleri. Toprak Bilimi ve Bitki Besleme Dergisi 3(1): 1-8.

DÇSD (1996) Türkiye'nin Ekonomik Değeri Olan Geofitlerin Üretimi ve Doğal Populasyonları Hakkında Rapor. Doğal Çiçek Soğancıları Derneği, İstanbul.

Dellavalle NB (1992) Determination of specific conductance in supertanat 1:2 Soil:Water Solution. In Handbook on Reference Methods for Soil Analysis. Soil and Plant Analysis Council, Inc. Athens,GA.

Eyüboğlu F (1999) Türkiye topraklarının verimlilik durumu. Toprak ve Gübre Araştırma Enstitüsü Yayınları, Genel yayın No: 220, Teknik Yayınlar No: T.67, Ankara.

FAO (1980) Soil and Plant Testing and Analysis as a Basis of Fertilizer Recommendations. FAO, Soils Bulletin 38/2, pp. 95.

FAO (1990) Micronutrient. Assessment at the Country Level: An International Study. FAO, Soil Bulletin by Mikko Sillanpaa. Rome.

Güçdemir İ (2006) Türkiye Gübre ve Gübreleme Rehberi. TC Tarım ve Köyişleri Bakanlığı Tarımsal Araştırmalar Genel Müdürlüğü Toprak ve Gübre Araştırma Enstitüsü Müdürlüğü Yayınları, Genel yayın No: 231, Teknik Yayınlar No: T.69, Ankara.

Hizalan E, Ünal H (1966) Topraklarda Önemli Kimyasal Analizler. A.Ü. Ziraat Fakültesi Yayınları: 278.

Jackson ML (1958) Soil Chemical Analysis. Prentice-Hall, Inc. Englewood Cliffs, New Jersey, USA, pp. 1-498.

Jackson ML (1962) Soil Chemical Analysis. Prentice Hall. Inc. New York, pp. 183.

Kacar B (1994) Bitki ve Toprağın Kimyasal Analizleri:III. Toprak Analizleri. Ankara Üniversitesi, Ziraat Fakültesi, Eğitim,Araştırma ve Geliştirme Vakfi Yayınları, No: 3, Isbn:975-7717-04-5, Ankara.

Kandemir N (1997) Bazı endemik iris (Irıdaceae) türleri üzerinde morfolojik, anatomik ve ekolojik bir araştırma. Yayınlanmamış Doktora Tezi, Ondokuzmayıs Üniversitesi, Fen Bilimleri Enstitüsü, Samsun.

Lindsay WL, Norvell WA (1978) Development of a DTPA soil test for zinc, 1ron, manganese and copper. Soil Sci. Amer. Jour. 42(3): 421428.

Olsen SR, Cole V, Watanable FS, Dean LA (1954) Estimation of available phosphorus in soils by extraction with sodium bicarbonate. USDA Circular 939, USDA. U.S. Government Printing Office, Washington, DC.

Palaz EB, Yılmaz CH, Aytop H, Büyükçıngıl Y (2018) Kahramanmaraş doğal florasında yetişen salep orkide bitkisinin mineral beslenme özellikleri ile yetiştiği toprakların bazı fiziksel ve kimyasal özelliklerinin incelenmesi. Türk Tarım ve Doğa Bilimleri Dergisi 5(4): 537-544.

Pizer NH (1967) Some advisory aspect: soil potassium and magnesium. Teck.Bull. No:14: 184.

Richards LA (1954) Diagnosis and improvement of saline and alkaline soils. U.S. Dept. of Agr. Handbook No: 60.

Sargın SA, Selvi S, Akçiçek E (2013) Alaşehir (Manisa) ve çevresinde yetişen bazı geofitlerin etnobotanik açıdan incelenmesi. Erciyes Üniversitesi Fen Bilimleri Enstitüsü Dergisi 29(2): 170-177. 
Uysal E, Kaya E (2017) Türkiye florasında doğal olarak yetişen farklı dağ lalesi (Anemone spp) türlerine ait toprakların bazı fiziksel ve kimyasal özellikleri. 5. Uluslararası Katılımlı Toprak ve Su Kaynakları Kongresi, Kırklareli, Bildiriler Kitabı (1): 176-184.

Uysal E, Kaya E (2018) Some soil properties of different asphodeline (Asphodeline spp.) species natural grown in flora of Turkey. $4^{\text {th }}$ International Symposium of Medicinal and Aromatic Plants, Çeşme/İzmir, Symposium Book, pp. 203-208.
Uysal E, Kaya E (2019) Türkiye florasında doğal olarak yetişen ve ilkbaharda çiçeklenen farklı acı çiğdem (Colchicum spp.) türlerine ait toprakların bazı fiziksel ve kimyasal özellikleri. Bahçe Yalova Atatürk Bahçe Kültürleri Merkez Araştırma Enstitüsü Dergisi 48(1): 9-18.

Uzunhisarciklı ME, Duman H, Y1lmaz S (2013) A New species of Bellevalia (Hyacinthaceae) from Turkey, Turkish Journal of Botany 37: 651-655. 